\title{
Increasing Childhood Influenza Vaccinations at the Community Pharmacy in Pennsylvania: Important Factors to Parents and Their Peers-A Pilot Study
}

D. Mayer, PharmD ${ }^{1}$; M. Frontino, PharmD, BCACP 2,3 ; P. Melissen, BSPharm, BCACP ${ }^{2}$; D. Yu, PhD ; N. Patel-Shori, PharmD, BCACP

${ }^{1}$ Jefferson College of Pharmacy; ${ }^{2}$ Acme Sav-on Pharmacy; ${ }^{3}$ Temple University School of Pharmacy; ${ }^{4}$ Lewis Katz School of Medicine at Temple University

\begin{abstract}
Objective: The primary objective was to identify factors that would motivate an adult to bring a child into the community pharmacy for an influenza vaccination via a pilot study conducted in Pennsylvania.

Design: This was a multi-site, cross-sectional, exploratory, survey-based pilot study.

Setting: Participants were identified at three grocery store community pharmacies in southeastern Pennsylvania.

Results: A total of 349 surveys were collected over the study period and 325 participant surveys were included in the analysis. Receiving a vaccine in fifteen minutes or less (140; 74\%) and not needing an appointment (142; 75\%) were the top motivating factors for parents. Privacy, increased knowledge, and pharmacist counseling were identified as motivating factors for ninety-five (51\%), eighty-nine (48\%), and eighty-four (45\%) parents, respectively. Cost was a barrier for eighty-eight parents (47\%). The motivators and barriers for peers, those without children who might influence a parental decision, were similar to those of parents, however, more peers identified a child friendly environment ( $45 \%$ vs. $32 \% ; p=0.02$ ) and pharmacist counseling (57\% vs. 45\%; $p=0.03$ ) as motivators.

Conclusion: The opportunity to receive an influenza vaccination quickly, without an appointment, are the most important factors to parents and peers. Factors of cost, counseling, and increased access to educational materials are of moderate importance.
\end{abstract}

Keywords: Pediatrics, immunizations, community pharmacy

\section{Introduction}

Infection with the influenza virus is a dangerous and costly epidemic that is responsible for substantial morbidity and mortality every year. During the 2015-2016 influenza season, the Centers for Disease Control and Prevention (CDC) reported an estimated 25 million influenza-related illnesses. ${ }^{1}$ This correlates to a substantial economic burden across all age groups. Annually, caregivers of young children infected with the influenza virus spend approximately $\$ 300-\$ 4000$ on medical care and lose 11-19 work hours while with their children in outpatient or emergency room visits. A parent of a hospitalized child loses an average of 73 work hours. ${ }^{2,3}$

Protection from this virus became part of the national agenda when metrics for preventative vaccination were included in the Healthy People campaign. The Healthy People 2020 ten year agenda included several measures specifically targeting vaccination rates for seasonal influenza in children, adolescents, and adults. Even many years after the launch of this campaign, the rates of seasonal influenza vaccinations for children, ages six months through seventeen years of age, are still well below the Healthy People 2020 goal of 70 percent. ${ }^{5-9}$ For the 2017-2018 influenza season, the national rate of early vaccination through November 2017 for children over six

Corresponding author: Danielle Mayer, PharmD

Assistant Professor, Department of Pharmacy Practice

Jefferson College of Pharmacy

901 Walnut St, Suite 901, Philadelphia PA 19107

P: 215-503-3107; Danielle.Mayer@jefferson.edu months of age was reported to be $38.8 \%$ by the CDC, compared to an early vaccination rate of $37.3 \%$ in the 2016 2017 influenza season and 39.2\% during the 2015-2016 influenza season. ${ }^{6,7}$ When looking at the overall vaccination rate for children six months to seventeen years of age, the national average for the 2015-2016 season was $59.3 \%$ compared to $59 \%$ during the $2016-2017$ influenza season. ${ }^{8,9}$ Similar rates are expected for the 2017-2018 influenza season. ${ }^{6}$

One facet of the national strategy to improve vaccination rates has been to make vaccinations more accessible to the public. As highly accessible healthcare providers, community pharmacists are in an ideal position to help increase these consistently low rates of vaccination. Pharmacists in many states are expanding their immunization practices to include providing routine vaccinations to children. ${ }^{10,11}$ According to the National Alliance of State Pharmacy Associations, 26 states allow pharmacists to administer some or all vaccines to individuals of any age and 17 states allow pharmacists to administer some vaccines to children but have restrictions at some age less than eighteen. ${ }^{11}$

In June 2015, the state of Pennsylvania passed legislation to allow pharmacists to administer the influenza vaccine to children nine years of age and older with parental consent. Effective August 25, 2015, licensed pharmacists in Pennsylvania were able to administer the influenza vaccine to this population, without a prescription, through a vaccine protocol. ${ }^{10}$ This presented an opportunity for community pharmacists in Pennsylvania to target a vulnerable population. 
Data from the CDC indicates that Pennsylvania vaccination rates for children ages thirteen to seventeen were $48.7 \%$ during the 2015-2016 influenza season and 53\% during the 2016-2017 influenza season, which is still below the national goal. ${ }^{12}$ It is unclear, at this time, if this small jump in vaccination rates was due to increased accessibility since the passing of this legislation. More needs to be done to investigate the perceptions of parents in order to determine what barriers exist and how to motivate them to vaccinate a child. This study sought to identify motivating factors and barriers to having a child receive an influenza vaccine in the grocery store chain community pharmacy setting in Pennsylvania, from the perspective of adult parents and peers.

A few studies have indicated that the decision to not conform to recommended vaccine guidelines could be impacted by a parent's information network. Although parents ultimately determine if a child will receive a vaccine, their decision is influenced by the people they interact with as well as the sources they consult. A parent is less likely to have their child vaccinated if the individuals and sources in their network recommend nonconformity. ${ }^{13}$ It is unclear if a parent's broader community would also effect the decision to vaccinate a child, and for this reason the perceptions of parental peers would be additive to the research in this area.

A few previous studies have focused on obtaining information on parental perceptions of children receiving pediatric vaccines. ${ }^{14,15} \mathrm{~A}$ study done by Healy et al. revealed that healthcare professionals may not have a good grasp on parental concerns when it comes to getting their children vaccinated. This survey-based study suggested that parents are far less concerned with the number of shots received at one time and the route of administration than what healthcare providers once thought. Another study performed by Deshpande et al. surveyed parents within a specific health network who had children eligible to receive an influenza vaccine at a community pharmacy in the state. Results from this study indicated that a majority of parents who had their children vaccinated obtained the vaccine after school hours and did not need to make an appointment. The authors concluded that pharmacist provided immunizations were perhaps more convenient for parents with children. ${ }^{14}$ Additional Information about parental perceptions of children receiving pediatric vaccines, specifically in the community pharmacy setting, is lacking. This study looks to further explore specific factors of convenience, in addition to other factors related to the community pharmacy setting. Finally, since the ability for pharmacists to provide influenza vaccinations to pediatric patients in Pennsylvania was a new authority as of June 2015 it is unclear, at this time, if parents in this state feel comfortable with pharmacists as immunization providers to children, as indicated in previous studies. ${ }^{10,14,15}$
The results from the present study provide additional insights into what would motivate a parent and their peers to get a child vaccinated, specifically in the community setting. If motivators and barriers can be identified, targeted interventions can be developed to better engage parents, guardians, caregivers, and other adults in the community whom may serve in the parent's information network.

\section{Objectives}

The primary objective of this study was to identify motivating factors that influence the decisions of parents, guardians, caregivers and adult community members, who may be in a parent's information network, in regards to having a child vaccinated at a grocery store chain community pharmacy in Pennsylvania. The secondary objective was to determine participants' confidence in community pharmacists as immunization providers for children in Pennsylvania.

\section{Methods}

Participants were identified and recruited to complete an anonymous survey at three pharmacy locations in southeastern Pennsylvania by any member of the pharmacy team that had been trained by the primary investigator. All adults were asked to participate in this study including: individuals who have children under eighteen years of age, individuals who have children over eighteen years of age, and individuals who do not have children. Participants less than eighteen years of age and participants who could not read in English were excluded from this study. All adults meeting the inclusion criteria, including parents and non-parents, were included in this study to try and capture the responses of both parents and those individuals who might be in their information network. ${ }^{14}$ This project was classified as exempt research through Temple University Investigational Review Board.

The survey assessed participant demographics, a child's influenza immunization history, and factors that could affect the decision to obtain a pediatric vaccine at the community pharmacy. Participant demographic information, parental status, and age information about children, if applicable, were gathered using check boxes. Participants were also asked to answer a series of questions on a 5-point Likert scale in order to characterize each item as a motivating factor or barrier for the participant. The full survey is available as Appendix 1.

Upon completion of the survey, all participants were eligible to receive a \$5 ACME Markets gift card, supported by grant funding through the American Pharmacists Association and Pennsylvania Pharmacists Association.

Paper surveys were coded based on pharmacy location and survey number, eliminating the need to record patient identifiable information. For those interested in receiving a gift card, the participant removed the last page of the survey 
containing their contact information and placed it into a closed, opaque file folder separate from the completed surveys. The contact information was used only to alert the patient when the gift card was available at the store for pickup.

Due to the exploratory nature of this study, no sample size or power calculations were performed. Survey data were analyzed and reported using descriptive summary statistics, including mean, median, range, and quartiles for a continuous variable and frequency and percentage for a categorical variable. Results were analyzed and compared based on the responses to, question one: "I am NOT a parent, guardian, or primary caregiver of a child or children" or "I am a parent, guardian, or primary caregiver of a child or children", and question three: "Would you get your child or children vaccinated at a community pharmacy?" respectively. This was done to identify motivating factors and/or barriers to vaccination at a community pharmacy.

Responses of "strongly agree" and "agree" were combined as one category "Agree" and responses for "neither agree nor disagree," "disagree," and "strongly disagree" were also combined into a second category of "Not Agree". The probability of "Agree" was compared between subgroups using the Chi-square test. Responses were combined into the described categories in order to detect a difference while accommodating for a data set with a majority of participants indicating "Agree" and "neither agree nor disagree" and a minority of patients indicated responses of "Strongly Agree" and "Strongly disagree". This improved the precision of percentage estimates and rates of "Agree" in order to facilitate comparisons of related variables between subgroups. The authors also wanted to present the readership with numerical data so that the results could be more clearly shown. The Wilcoxon test was employed to compare continuous variables between subgroups. Responses to survey question eleven: "I am comfortable getting my child/children vaccinated for the flu by the community pharmacist" was used to evaluate participant confidence in pharmacists as immunization providers.

A p-value $<0.05$ was considered statistically significant. All statistical analyses were performed using SAS V9.3 software (SAS Institute Inc., Cary, NC).

\section{Results}

A total of 349 surveys were collected over the study period from December 2015 to April 2016. A total of seventy eligible participants declined to take the survey resulting in an $83 \%$ response rate. Overall, 325 surveys were included in the final analysis. The following participants were excluded from the analysis: 1) participants indicating that vaccines were not beneficial to their health or the health of their children $(n=12)$ and 2) participants declining to answer if they were parents $(n=12)$.

All participants who indicated they were a parent, guardian, or caregiver were classified as parents and all participants who indicated they were not a parent, guardian, or caregiver were classified as peers, for research analysis.

The median age of the survey participants was 52 (interquartile $38-60$ ) years of age and $36 \%$ were male and $63 \%$ were female with four participants (1\%) not indicating their sex. Participants were primarily Caucasian (69\%) and African American (23\%) with the remaining participants indicating a variety of other races. The demographic information was similar between parents and peers as described in Table 1.

The only significant difference, between the parents and peers groups, was in level of education. Among parents, ninety-five (50\%) had a college degree compared to ninety-two (49\%) that did not, indicating a more equal split in education level within this group. Comparatively, 101 peers (74\%) had a college degree or above and thirty-three $(24 \%)$ did not $(p<0.0001)$.

One hundred and eighty-nine participants (58\%) indicated that they were parents for at least one child and 136 (42\%) indicated that they were not. Parents were asked to identify the age group of their child or children and could select more than one category if they had children in multiple age groups. Fifty-four parents (29\%) indicated that they had at least one child between the ages of zero and eight years of age, sixtythree parents (33\%) indicated they had at least one child between nine and seventeen years of age, and 105 parents $(56 \%)$ indicated they had at least one child over the age of eighteen as shown in table 1. Overall for the parent group, 106 parents $(57 \%)$ had at least one child under the age of eighteen and 80 parents $(43 \%)$ had children only eighteen years of age or older. Three parents (2\%) did not indicate the age of their children.

Receiving a vaccine in fifteen minutes or less $(140 ; 74 \%)$ and not needing an appointment $(142 ; 75 \%)$ were identified as the top factors that would encourage parents to vaccinate their children at a community pharmacy as shown in figure 1 . Privacy for vaccine administration was identified as a motivator for ninety-five parents (51\%) and increased parent knowledge through community education and pharmacy counseling were identified as motivating factors for eightynine(48\%) and eighty-four (45\%) parents, respectively. Additionally, only sixty-one parents (32\%) indicated that a more child friendly environment would be a motivation for them to bring their child into a community pharmacy for vaccination. Cost was identified as a barrier for eighty-eight parents $(47 \%)$ in the current climate where most influenza vaccinations are covered at little to no cost under third party plans, as depicted in figure 1 . When analyzing question eleven 
on the survey: "I am comfortable getting my child/children vaccinated for the flu by the community pharmacist", 148 parents (79\%) indicated "Agree" with the statement.

When comparing responses between parents with only children eighteen years of age or older and those with at least one child under 18 , no statistically significant differences in factors were found except for the factor of additional counseling. Forty-two parents with children only eighteen or older (53\%) indicated that they agreed or strongly agreed that more counseling would be a motivator for them while only forty parents (38\%) in the group with at least one child under 18 answered agree or strongly agree. $(p=0.037)$.

The motivators and barriers for peers were similar to those of parents, however more peers identified a child friendly environment ( $45 \%$ vs $32 \% ; p=0.02$ ) and pharmacist counseling ( $57 \%$ vs. 45\%; $p=0.03$ ) as motivators as depicted in Figure 1.

A total of 280 participants answered question three: "Would you get your child or children vaccinated at a community pharmacy?" Of those who answered, a total of 237 participants $(85 \%)$ indicated that they would go to the community pharmacy for a pediatric vaccination ("yes" group) and 43 participants (15\%) indicated that they would not ("no" group). The most commonly identified motivating factors by the "yes" group included no appointment needed and being able to receive a vaccine in 15 minutes or less $(84 \%$ and $87 \%$ respectively). The "no" group, however, most commonly identified factors of privacy and a child-friendly environment (39\% and 29\% respectively) as shown in Figure 2.

Further analysis was completed based off responses to question three of the survey in order to determine if any differences in motivating factors existed between parents who would or would not get a child vaccinated at a community pharmacy. Parents who answered that they would get a child vaccinated at the pharmacy were labeled "yes parent" and those who indicated they would not were labeled "no parent". The same analysis was done with the peer group. Peers who would, theoretically, get a child vaccinated at a community pharmacy were labeled "yes peer" and those who indicated they would not were labeled "no peer".

Overall in the parent group, 132 parents (81\%) indicated they would get a child vaccinated at a community pharmacy and 30 parents (19\%) indicated they would not. These groups are labeled "yes parent" and "no parent" respectively. Additionally, 105 peers (89\%) indicated they would get a child vaccinated at a community pharmacy and 13 peers (11\%) indicated they would not. These groups are labeled "yes peer" and "no peer", respectively. Twenty-seven parents (17\%) and eighteen peers (15\%) did not answer the question as shown in table 2 . The average age of parents in the "yes parent" and "no parent" groups were similar: 50 and 49 years of age, respectively. The average age of the "yes peer" group was 49 and 39 for the "no peer" group.

Of those in the "yes parent" group, receiving a vaccine in fifteen minutes or less and not needing an appointment were most commonly indicated as motivating factors compared to the "no parent" group (117; $89 \%$ vs 5; $17 \%$; Chi-square $p<0.0001$ and $114 ; 86 \%$ vs $8 ; 27 \%$; Chi-square $p<0.0001$ ). Similar results were seen in the "yes peer" group compared to the "no peer" group ( $89 ; 85 \%$ vs $3,25 \% ; p<0.0001$ and $85 ; 82 \%$ vs $1 ; 8 \% ; p<0.0001)$.

Statistically significant differences between the parent groups were also seen for factors of cost, increased education, and counseling compared to statistically significant differences in more privacy and cost in the peer group as shown in Table 2.

\section{Discussion}

Changes in state pharmacy laws, such as the change made in Pennsylvania, that lower the minimum age for vaccine administration have expanded the role of a pharmacist as an immunization provider. ${ }^{10}$ Despite this expansion in accessibility, data from the CDC indicates that vaccination rates for children are below the national goal year after year. ${ }^{6-}$ ${ }^{9}$ We must understand the factors that guide a parent's decision to have their child vaccinated in order to positively affect public health efforts and support the continued expansion of immunization services to children. Results from this study helped to clarify parent and peer perspectives in a grocery store chain community pharmacy and provide support to factors that may have been intuitively targeted.

Results of this study showed, the opportunity to receive an influenza vaccination quickly, without an appointment, is the most important motivating factor to parents and peers. This indicates that pharmacies should be sufficiently staffed, especially during flu season, so that the pharmacist is readily available to step out of workflow for vaccine administration quickly and safely. Since accessibility is one of the primary advantages of the community pharmacy, it is important to make sure that pharmacists are available to educate parents and administer vaccines. Additionally, pediatric vaccine protocols in community pharmacies are relatively new in many states, especially Pennsylvania; so adequate education needs to be done to make sure parents and peers know they can bring a child into the pharmacy without an appointment. Due to the potential role of a parent's information network, expanding education about new vaccine protocols to the broader community is important. Our study results provide additional insights into factors of convenience as they relate to the findings of the study performed by Deshpande et al. discussed in the introduction. ${ }^{14}$ This is an important consideration as national rates for childhood influenza vaccinations remain below the national goal., 
This study also showed that factors of cost, counseling, and increased access to educational materials are moderate motivators for parents and peers. This is an important addition to the current body of research, as previous studies have focused primarily on administration and convenience factors. In today's healthcare climate, many third-party payers cover influenza vaccinations at no cost to the parent; however $47 \%$ of parents still indicated that cost was a barrier. All sectors of the healthcare system including pharmacists, physicians, and third-party payers must come together to expand vaccination coverage and educate parents on where they are able to go to receive a pediatric vaccine. Pharmacists must continue to advocate for the profession and our role in immunization programs so that our services are more accessible to the community. It is also crucial to continue education campaigns that explain the importance of preventative vaccines and the pharmacist's role in administering the pediatric influenza vaccine.

Contrary to initial thought, privacy was not the primary motivator for parents. Furthermore, a child-friendly environment was not a strong factor that parents indicated they consider when deciding to get their child the pediatric influenza vaccine. These results show that major structural changes to create full patient care rooms with child-friendly waiting areas may not be as important to parents as other factors such as convenience and time. Having a semi-private area with enough space for a parent and child to receive a vaccine comfortably may be enough for a parent if they could come in to get their child vaccinated without an appointment or a long wait time. These factors were perceived as motivators for peers, indicating additional education may be warranted for this group. The only factors that were identified as significantly different between the parents and peers groups were the factors of more counseling by the pharmacist and a child-friendly environment. The results of this study expand on the body of existing evidence in regards to parental and peer perceptions in the setting of a grocery store chain community pharmacy in Pennsylvania. Prior to legislation changes, children under eighteen in Pennsylvania have had to receive influenza vaccinations in physician offices, so it was thought that in order for parents and their children to feel comfortable at a community pharmacy it would not only have to be convenient, as indicated in previous research, but the setting would also have to mirror that of a pediatric office with private rooms and a child-friendly atmosphere. Our results have important implications, as the data show that our initial perceptions were not correct. Additional studies need to be performed to identify if these parental and peer perceptions exist across the state and in different community pharmacy settings, such as large chain and independent retailers.

As stated previously, research done in the outpatient setting and in other states indicates that parents feel comfortable with pharmacists as immunization providers. ${ }^{14,} 15$ This study confirms this perception for parents and peers who use a grocery store chain community pharmacy in Pennsylvania. This is important information to consider as pharmacists in Pennsylvania determine how they will best expand their immunization services to include vaccination for children nine and up. If parents and peers already feel comfortable, then emphasizing the other factors discussed in this article could provide a parent with the needed incentive to get their child vaccinated.

Future research could investigate if similar trends are seen in different community pharmacy settings across the entire state of Pennsylvania. It would also be beneficial to explore these trends on a national level to determine if these factors are applicable to multiple state immunization efforts. If further research was to be completed, more rigorous validation of the survey instrument and sample size or power calculations would enhance the validity of the data collected.

Additionally, it may be beneficial to explore if the advice of a pediatrician or primary care physician to have a child vaccinated at the community pharmacy would influence acceptance rates. At the time of this study, the legislation had changed immediately prior to the start of the influenza season and this factor was not explored, as it was anticipated that very few parents would have known about the change. The survey tool did, however, collect data on whether or not a child was vaccinated the previous year and if the parent would get them vaccinated at a community pharmacy during that flu season. This data was inconclusive, as $42 \%$ of parents did not report this information.

Additional data needs to be collected in order to determine what factors might influence those parents and peers who do not feel comfortable getting a child vaccinated at the community pharmacy currently. This study was unable to identify any factors that would be important enough to motivate these individuals to use the community pharmacy as a setting for childhood influenza vaccine administration.

\section{Limitations}

There are limitations present in this study. Due to the exploratory nature of this study, the authors did not complete a sample size or power calculation. Participants were approached to participate in the study while they were in the grocery store, including the self-care aisles, shopping, or at the pharmacy. Although participants did not have to be a pharmacy customer to participate, many were already pharmacy customers. These participants often had existing relationships with the pharmacists or technicians which may have led them to answer questions in a way that reflected more favorably on the pharmacy and staff. The ability of participants to obtain a \$5 ACME Markets gift card for their participation could have also resulted in similar favorable survey outcomes. We attempted to minimize this risk by 
administering written anonymous surveys rather than performing face-to-face or telephonic interviews. Future studies could consider requesting the survey be mailed to a third party collector, if such resources are available.

Additionally, participants coming to the pharmacy to pick up medications or to ask a medication related question are already invested in their personal health and wellness. Patients and peers that are invested in their health are more likely to place a priority on preventative health services and may have more positive views on getting a child vaccinated at a community pharmacy. Surveying patients in more diverse settings may enhance the generalizability of future data.

This study was performed in several sites in southeastern Pennsylvania in response to the recent changes to pharmacy regulations. Although the overall vaccination rates in Pennsylvania are similar to the national averages, a more national data sample is needed to determine if similar barriers and motivators exist across the entire state and country.

Additional limitations existed in the validation of the survey instrument itself. The survey instrument was tested in a small sample of individuals, both parents and peers, to establish face validity prior to administration. Additional validation utilizing principal components analysis and internal consistency were not performed. If future studies were to be done to expand on this pilot study, further validation of the survey instrument would enhance the validity of the data collected.

Finally, due to the nature of data collection, some surveys had missing or incomplete information. Missing information was indicated as best as possible in the presentation of the results. The authors did not perform Bonferroni corrections for multiple comparisons.

\section{Conclusion}

Community pharmacists are well positioned to have a major impact on public health efforts to increase vaccination rates amongst all age groups in the community. Results from this study helped to clarify parent and peer perspectives and provide support for the implementation of interventions that target the identified motivators and barriers in Pennsylvania.
Acknowledgements: The authors would like to thank the ACME Sav-on Pharmacy teams for their assistance in data collection. We thank the TOP TIER (Training Outpatient Pharmacists Techniques In Evidence-Based Research) team; Jeff Hamper, PharmD; and the Acme Sav-on Pharmacy residency team for their assistance with project development.

Funding and Conflict of Interest Statement: This work was supported by the American Pharmacists Association Incentive Grant and Pennsylvania Pharmacists Association Educational Foundation Grant.

We declare no conflicts of interest or financial interests that the authors or members of their immediate families have in any product or service discussed in the manuscript, including grants (pending or received), employment, gifts, stock holdings or options, honoraria, consultancies, expert testimony, patents and royalties.

\section{References}

1. Centers for Disease Control and Prevention. Estimated Influenza Illness, Medical Visits, Hospitalizations, and Deaths Averted by Vaccination in the United States. https://www.cdc.gov/flu/about/disease/201516.htm Accessed August 16, 2017.

2. Ortega-Sanchez IR, Molinari NA, Fairbrother $\mathrm{G}$ et al. Indirect, out-of-pocket and medical costs from influenza-related illness in young children. Vaccine. 2012; 30:175-81.

3. Centers for Disease Control Foundation. Flu Prevention. www.cdcfoundation.org/businesspulse/fluprevention-infographic. Accessed May 31, 2017.

4. Ozawa S, Portnoy A, Getaneh H, et al. Modeling the economic burden of adult vaccine-preventable diseases in the United States. Health Aff. 2016; 35:11.

5. U.S. Department of Health and Human Services. Healthy People 2020: topics \& objectivesimmunization and infectious diseases. http://www.healthypeople.gov/2020/topicsobjectives/topic/immunization-andinfectiousdiseases/objectives. Accessed October 23, 2015.

6. Centers for Disease Control and Prevention. National Early-Season Flu Vaccination Coverage, United States, November 2017. https://www.cdc.gov/flu/fluvaxview/nifs-estimatesnov2017.htm. Accessed December 11, 2017. 
7. Centers for Disease Control and Prevention. National Early-Season Flu Vaccination Coverage, United States, November 2016. https://www.cdc.gov/flu/fluvaxview/nifs-estimatesnov2016.htm. Accessed May 31, 2017.

8. Centers for Disease Control and Prevention. Surveillance of influenza vaccine coverage- United States, 2015-2016 influenza seasons. https://www.cdc.gov/flu/fluvaxview/coverage1516estimates.htm. Accessed May 31, 2017.

9. Centers for Disease Control and Prevention. Surveillance of influenza vaccine coverage- United States, 2016-2017 influenza seasons. https://www.cdc.gov/flu/fluvaxview/coverage1617estimates.htm. Accessed December 11, 2017.

10. State of Pennsylvania. 2015 Act 8-Authory to Administer Injectable Medications, Biologicals and Immunizations.http://www.legis.state.pa.us/cfdocs/I egis/li/uconsCheck.cfm?yr=2015\&sessInd=0\&act=8. Accessed September 25, 2015.

11. Weaver K. Pharmacist-administered immunizations: What does your state allow? Pharm Today. 2015; 15:62-3.

12. Centers for Disease Control and Prevention. FluVaxView 2015-2016 and 2016-2017 influenza seasons. https://www.cdc.gov/flu/fluvaxview/reportshtml/re porti1415/reporti/index.html. Accessed December 11, 2017.

13. Brunson, E. The impact of social networks on parents' vaccination decisions. Pediatrics. 2013; 131:1397-1404.

14. Healy CM, Montesinos DP, Middleman AB. Parent and provider perspectives on immunization: Are providers overestimating parental concerns? Vaccine. 2014; 32:579-84.

15. Deshpande M, Schauer J, Mott DA, Young HN, et al. Parents' perceptions of pharmacists as providers of influenza vaccine to children. J Am Pharm Assoc. 2013; 53:488-95. 
Figure 1: Motivating Factors Identified by Parent and Peer Groups

I would be more likely to get my child or children vaccinated if:

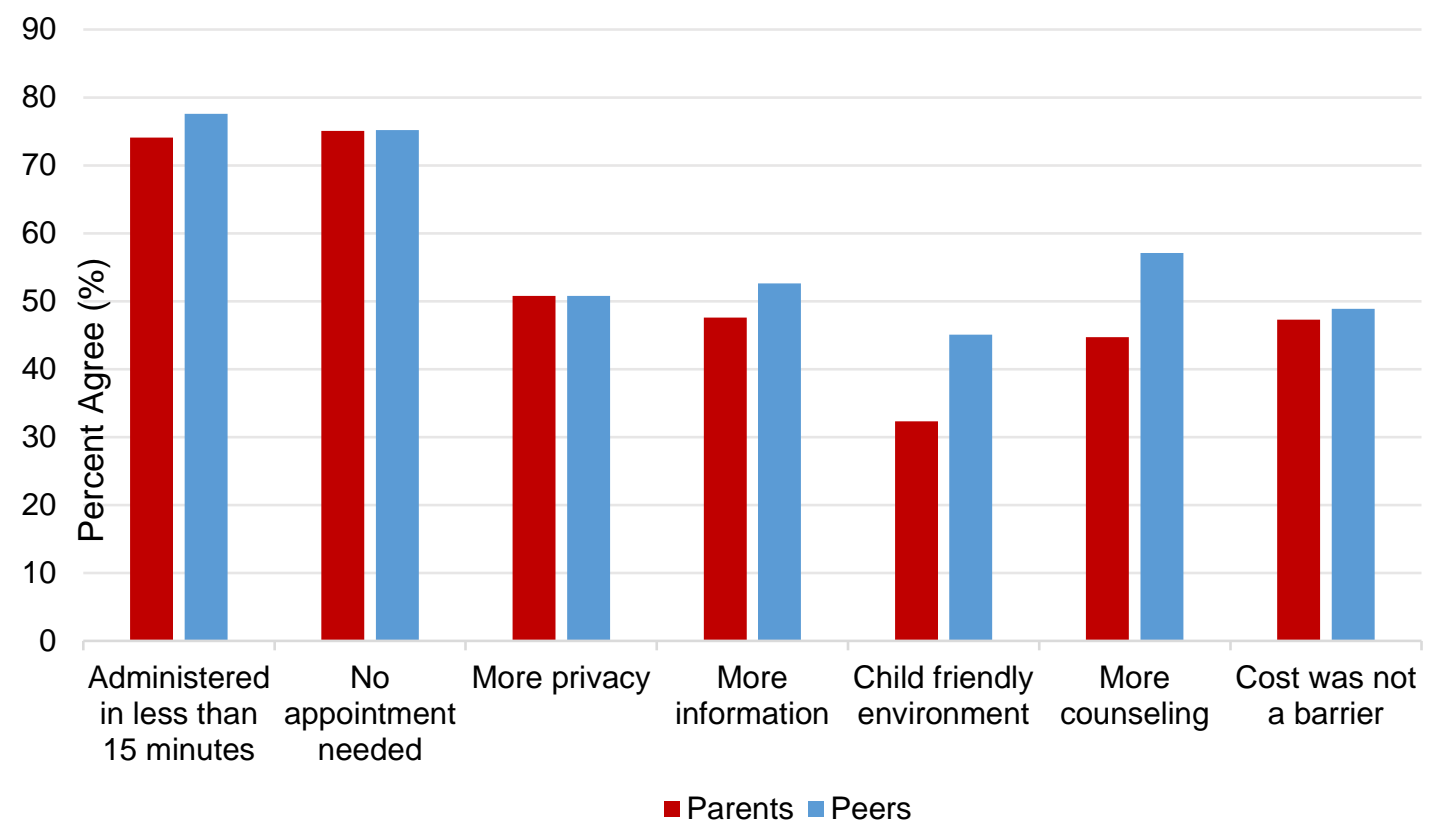

*Missing data for the above variables: 2 peer <15min, 3 peer no appointment, 4 peer and 2 parent privacy, 3 peer and 2 parent information, 3 peer environment, 3 and 1 parent peer counseling, and 3 peer and parent cost 
Figure 2. Comparison of motivating factors between participants who answered yes versus those who answered no to survey question three.*

I would be more likely to get my child or children vaccinated if:

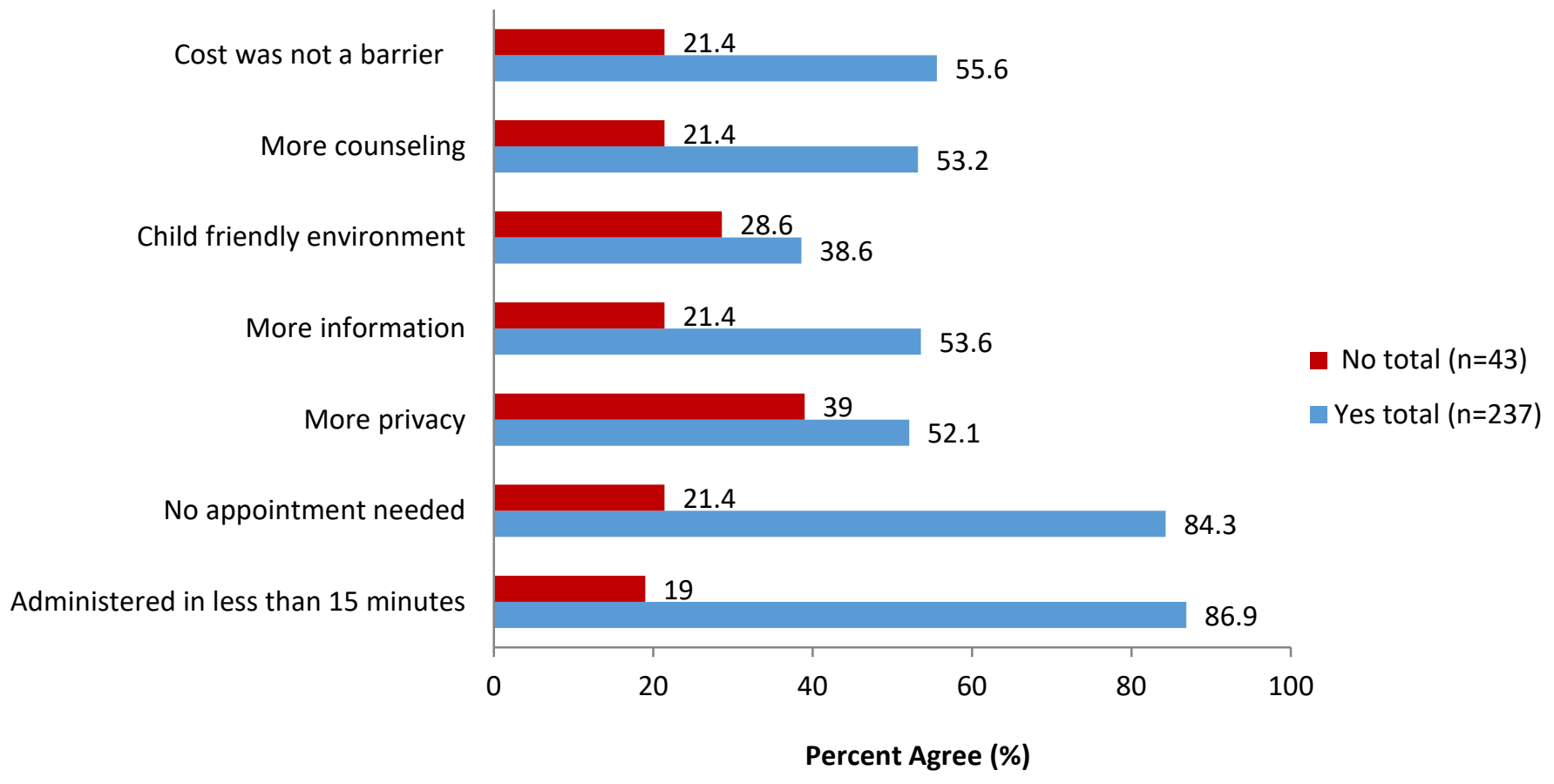

*Question 3: Would you get your child or children vaccinated at a community pharmacy? 
Table 1. Characteristics of Parent and Peer Groups

\begin{tabular}{llll}
\hline & $\begin{array}{l}\text { Parents }(\mathrm{n}=189) \\
\text { no. }(\%)\end{array}$ & $\begin{array}{l}\text { Peers }(\mathrm{n}=136) \\
\text { no. }(\%)\end{array}$ & p-value \\
\hline Sex* & & & 0.99 \\
\hline Male & $67(35.4)$ & $48(35.3)$ & \\
Female & $120(63.5)$ & $86(63.2)$ & 0.82 \\
\hline Age (mean)** & $50 \pm 14$ & $49 \pm 18$ & 0.97 \\
\hline Race/ethnicity* & & $95(69.9)$ & \\
\hline Caucasian & $130(68.8)$ & $30(22.1)$ & \\
African American & $44(23.3)$ & $1(0.7)$ & \\
Hispanic/Latino & $3(1.6)$ & $3(2.2)$ & \\
Asian/Pacific Islander & $1(0.5)$ & $5(3.7)$ & \\
Other & $9(4.8)$ & & \\
\hline Education* & & $33(24.3)$ & \\
\hline less than high school to high & & $101(74.3)$ & \\
school or equivalent & $92(48.7)$ & & \\
College or above & $95(50.3)$ & - & \\
\hline Age of children in the family*** & & - & \\
\hline 0-8 & $54(28.6)$ & & \\
9-17 & $63(33.3)$ & $105(55.6)$ & \\
18 and above &
\end{tabular}

*2 parents and peers did not disclosure sex, race, or education

**2 parents and 3 peers did not disclosure age

***3 parents did not disclose the age of their children. Parents could select multiple age groups 
Table 2. Comparison of motivating factors between parents and peers who would get a child or children vaccinated at the community pharmacy and those who indicated they would not.

\begin{tabular}{llll}
\hline Parents [no. (\%)] & & & \\
\hline & Yes Parent $(n=132)$ & No Parent $(n=30)$ & $p$-value* \\
Administered in less than 15 minutes & $117(88.6)$ & $5(16.7)$ & $<0.0001$ \\
No appointment needed & $114(86.4)$ & $8(26.7)$ & $<0.0001$ \\
More privacy & $69(53.1)$ & $12(40)$ & 0.20 \\
More information & $69(51.7)$ & $6(20)$ & 0.001 \\
Child friendly environment & $45(34.1)$ & $9(30)$ & 0.67 \\
More counseling & $64(48.9)$ & $5(16.7)$ & 0.001 \\
cost was not a barrier & $72(55.4)$ & $7(23.3)$ & 0.002 \\
\hline Peers [no. (\%)] & & & $\mathrm{p}$-value* \\
\hline & Yes Peer (n=105) & $<0.0001$ \\
Administered in less than 15 minutes & $89(84.8)$ & $3(25)$ & $<0.0001$ \\
No appointment needed & $85(81.7)$ & $1(8.3)$ & 0.36 \\
More privacy & $53(51)$ & $4(36.4)$ & 0.05 \\
More information & $57(54.8)$ & $3(25)$ & 0.20 \\
Child friendly environment & $46(44.2)$ & $3(25)$ & 0.09 \\
More counseling & $61(58.7)$ & $4(33.3)$ & 0.01 \\
cost was not a barrier & $58(55.8)$ & $2(16.7)$ & \\
\end{tabular}

*27 participant surveys had missing data in the yes/no parent group and 18 had missing data in the yes/no peer group 


\section{Appendix 1:}

ACME SAV-On Pharmacy

Temple University

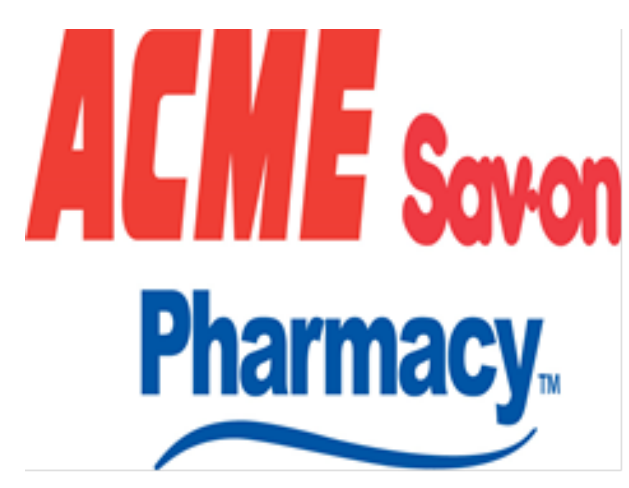

\section{Flu Vaccination Patient Survey}

Background: In June of 2015 the Governor of Pennsylvania passed an act that allows licensed, trained pharmacists to provide the flu vaccine to children nine years of age and older with parental consent. This act is effective as of August $25^{\text {th }}, 2015$.

The responses provided will be completely anonymous and your individual results will not be shared with your doctor or any other health care professional. This survey is completely voluntary and you can skip any questions that you feel uncomfortable answering.

Fill out the last page of this survey only if you wish to receive a \$5 ACME gift card. The last page will be detached from the survey.

Each participant should fill out this survey only ONE time.

Survey Number:

PLEASE CHECK HERE IF YOU HAVE TAKEN THIS SURVEY BEFORE 


\section{Flu Vaccination Patient Survey}

I do NOT believe vaccines are beneficial to my health or the health of my child/children. (If you checked the box skip to question 12 on page 4. If you did NOT check this box continue below)

1. Please check one of the following:

I am a parent, guardian, or primary caregiver of a child or children.

I am NOT a parent, guardian, or primary caregiver of a child or children.

(If you checked this box skip to question 3 on the next page)

2. If you are a parent, guardian, or primary caregiver of a child or children please answer the following questions:

A. How old is your child or children? (select all that apply)

$$
\text { 0-8 years old } \square \text { 9-17 years old } \square \text { Over } 18 \text { years old }
$$

ALL child/children over 18 years old (If you checked skip to question 3 on the next page)

B. If you have a child or children under 18 , did they get a flu shot last year (2014)?

Yes $\square$ No $\square$ I don't know

C. If you have a child or children under 18 , do you plan to get them a flu shot this year (2015)?

Yes $\square$ No $\square$ I don't know

D. If you have a child or children under 18 , did you get them vaccinated or plan on getting them vaccinated at a community pharmacy this year (2015)?

Yes $\square$ Will do so in the near future $\square$ No $\square$ I don't know

If you have taken this survey before please alert the pharmacy team 


\section{Flu Vaccination Patient Survey}

Please answer questions 3- 11 to the best of your ability even if you do not have a child or children under the age of 18.

\section{Would you get your child or children vaccinated at a community pharmacy?}

$$
\text { Yes } \quad \square \text { No }
$$

\begin{tabular}{|c|c|c|c|c|c|}
\hline Please rate these statements about the flu shot. & $\begin{array}{l}\text { Strongly } \\
\text { Agree }\end{array}$ & Agree & $\begin{array}{l}\text { Neither } \\
\text { agree nor } \\
\text { disagree }\end{array}$ & Disagree & $\begin{array}{l}\text { Strongly } \\
\text { disagree }\end{array}$ \\
\hline $\begin{array}{l}\text { 4. I would be more likely to get my } \\
\text { child/children vaccinated by a community } \\
\text { pharmacist if an immunization could be } \\
\text { administered in } 15 \text { minutes or less. }\end{array}$ & & & & & \\
\hline $\begin{array}{l}\text { 5. I would be more likely to get my } \\
\text { child/children vaccinated by a community } \\
\text { pharmacist if I did NOT need to make an } \\
\text { appointment to get my child/children } \\
\text { vaccinated. }\end{array}$ & & & & & \\
\hline $\begin{array}{l}\text { 6. Cost is a major barrier when deciding where } \\
\text { to get my child/children vaccinated. }\end{array}$ & & & & & \\
\hline $\begin{array}{l}\text { 7. The level of privacy that my child/children and } \\
\text { I receive is a major factor in deciding where to } \\
\text { get my child/children vaccinated. }\end{array}$ & & & & & \\
\hline $\begin{array}{l}\text { 8. I would be more likely to get my } \\
\text { child/children vaccinated by a pharmacist at a } \\
\text { community pharmacy if I knew more about } \\
\text { the flu vaccine. }\end{array}$ & & & & & \\
\hline $\begin{array}{l}\text { 9. I would be more likely to get my } \\
\text { child/children vaccinated at a community } \\
\text { pharmacy if my pharmacy was more child } \\
\text { friendly (had toys, books, and more pictures). }\end{array}$ & & & & & \\
\hline $\begin{array}{l}\text { 10. I would be more likely to get my } \\
\text { child/children vaccinated at a community } \\
\text { pharmacy if I received more counseling about } \\
\text { the flu vaccine by the pharmacist. }\end{array}$ & & & & & \\
\hline $\begin{array}{l}\text { 11. I am comfortable getting my child/children } \\
\text { vaccinated for the flu by the community } \\
\text { pharmacist. }\end{array}$ & & & & & \\
\hline
\end{tabular}

If you have taken this survey before please alert the pharmacy team 


\section{Flu Vaccination Patient Survey}

Please answer the following demographic questions to the best of your ability:

1. How old are you?

2. What is your sex?

$\square$ Male $\square$ Female

3. What is your ethnic origin or race?

$\square$ Caucasian $\square$ African American $\square$ Hispanic or Latino $\square$ Native American $\square$ Asian/ Pacific Islander $\square$ Other

4. What is the highest degree or level of school you have completed?

Some high school $\square$ High school graduate or the equivalent $\square$ College or above 


\section{Flu Vaccination Patient Survey}

Please enter the following information ONLY if you wish to receive a \$5 ACME gift card. Please detach this form and place in the anonymous survey box. If you have already filled out this survey once please alert the pharmacy staff.

Full Name:

Address:

Phone number: 